\title{
Measurement of Carbonyls in Three Urban Zones of the Mexico City Metropolitan Area and One Rural Zone
}

\author{
Armando P. Baez , María del Carmen Torres, Rocío García, Hugo Padilla and Raúl Belmont \\ Centro de Ciencias de la Atmósfera, Laboratorio de Química Atmosférica, Universidad Nacional Autónoma de México, \\ Ciudad Universitaria, México D.F., 04510, México
}

\begin{abstract}
C}_{1}-\mathrm{C}_{5}$ carbonyl compound concentrations were measured at four sites; three urban sites in the Mexico City Metropolitan Area (MCMA) and a rural site in the state of Morelos during the period 2006-2007. Formaldehyde, acetaldehyde and acetone were found to be the most abundant carbonyls, with acetone showing the highest levels at all sites. Concentrations were highest in winter at all sites and lower in summer and autumn. These decreases in concentration are explained by the influences of both photochemical reactions and local meteorological conditions. The strong correlation between $\mathrm{C}_{1}-\mathrm{C}_{2}$ and $\mathrm{C}_{3}$ indicated a common origin for these carbonyls. This was supported by a factor analysis which showed high loading on $\mathrm{C}_{1}-\mathrm{C}_{2}$ and $\mathrm{C}_{3}$. The $\mathrm{C}_{1} / \mathrm{C}_{2}$ ratios varied between 0.77 to 1.19 , values which can be considered typical of an urban area.
\end{abstract}

Keywords: Carbonyl compounds; day-night time and seasonal variations; emission sources.

\section{INTRODUCTION}

Carbonyls are common constituents of rural and urban atmospheres $[1,2]$ and are of particular interest due to their potential impact on health. They are emitted by many mobile and stationary sources [3], but they also exist as secondary carbonyl intermediates in the photo-oxidation of organic compounds in the atmosphere [4]. In general, these compounds have been shown to play an essential role in photochemical reactions in the troposphere and also in the lower stratosphere [5]. Among the carbonyls, formaldehyde and acetaldehyde are the most abundant in the urban atmosphere [6,7]. Formaldehyde has been the most studied, since it is classified in group 2A (probable human carcinogen) by the International Agency for Research on Cancer due to its carcinogenicity [8]. The direct release of both aldehydes from internal combustion engines has been found to increase with the use of reformulated fuel blended with methyl-tert-butyl-ether (MTBE) [9, 10]. This fuel is currently used in Mexico. Due to their main chemical and physical pathways, the lifetimes of formaldehyde and acetaldehyde in the troposphere have been estimated to be on the order of several hours in summer [11]. Both compounds can therefore be transported over distances of some kilometers, leading to significant photochemical pollution effects in metropolitan areas. Oxygenated fuel with MTBE as an additive has produced relatively high concentrations of formaldehyde and acetaldehyde in the atmosphere of Mexico City [12]. For this reason it was decided to measure not only formaldehyde and acetaldehyde but also acetone, propionaldehyde and butyraldehyde at three urban Mexico city sites and one rural site in the contiguous state of

*Address correspondence to this author at the Centro de Ciencias de la Atmósfera, Laboratorio de Química Atmosférica, Universidad Nacional Autónoma de México, Ciudad Universitaria, México D.F., 04510, México; Fax: (525) 5622-4050; E-mail: barmando@troposfera.atmosfcu.unam.mx
Morelos at a location $50 \mathrm{~km}$ southeast of Mexico City, in order to find the variations in concentration of these carbonyls as a function of the seasons of the year and time of day.

\section{MATERIALS AND METHODS}

\subsection{Sampling Sites}

Four sites were chosen for the measurement of ambient carbonyls: the first was a heavily industrialized area (Tlalnepantla) in the state of Mexico in the northern part of Mexico City, the second (Cuauhtémoc) in downtown Mexico City, characterized by a high density of traffic on large avenues and narrow streets, the third (Coyoacán) in a residential area of Mexico City, and the last in a wooded rural area in the state of Morelos.

\subsection{Sampling}

Samples were collected with a Sep-Pak DNPH-Silica cartridge (Waters, Milford, USA) throughout the year during the sampling period 2006-2007. The downstream end of the cartridge was connected to a calibrated flow meter. Air was passed through the cartridge at a flow rate of $11 \mathrm{~min}^{-1}$ at 12 hour intervals (day and night), from 8:00 to 20:00 and from 20:00 to 8:00. An ozone scrubber was connected to the upstream end of the cartridge to avoid degradation of hydrazone derivatives [13]. Each cartridge was immediately sealed with Teflon caps, then wrapped in aluminum foil and refrigerated.

\subsection{Analytical Methods}

Cartridges were eluted with $10 \mathrm{ml}$ of HPLC grade acetonitrile, and $20 \mu 1$ aliquots were injected into a Perkin Elmer liquid chromatograph with an Isocratic pump (Norwalk, CT, USA). The analytical conditions were as follows: a spherisorb S5ODA2 reverse phase analytical column, water/acetonitrile $45 / 55 \mathrm{v} / \mathrm{v}$ as a mobile phase and a 
flow rate of $1 \mathrm{ml} \mathrm{min}{ }^{-1}$, derivatives were detected at $360 \mathrm{~nm}$ with a GBC LC $1200 \mathrm{UV} / \mathrm{V}$ is detector. Calibration was done by direct injection of standard mixtures with known amounts of solid hydrazones dissolved in acetonitrile. These standard mixtures gave linear responses up to $50 \mathrm{ppm}$ of the corresponding hydrazones.

Cartridge laboratory blanks and cartridge field controls were analyzed to determine background levels of DNPH derivatives. The average concentrations and standard deviations of cartridge laboratory blanks from five lots were $0.47 \pm 0.30, \quad 0.39 \pm 0.12$ and $0.92 \pm 0.48 \mu \mathrm{g} /$ cartridge for formaldehyde, acetaldehyde and acetone respectively. Propionaldehyde and butyraldehyde were detected but at levels near their detection limits. These results were then subtracted from the sampling results. Carbonyls in cartridge field controls were similar to those of the cartridge laboratory blanks.

The analytical detection limits for formaldehyde, acetaldehyde, acetone, propionaldehyde and butyraldehyde derivatives were $43,27,20,17$ and $11 \mu \mathrm{g}^{-1}$ respectively. Cartridge efficiency was determined by connecting two cartridges in series. Values of $>95 \%$ were obtained for all carbonyls using the sampling conditions described above. Sampling precision was determined from four co-located sampling devices operated simultaneously on six occasions. The results ranged from 0.3 to $12.1 \%$ RSD.

\section{RESULTS AND DISCUSSION}

Arithmetic mean, minimum, maximum and standard deviation of carbonyl concentrations measured in outdoor air at the four sampling sites during 2006 and 2007 are shown in Table 1. The results varied from one site to another, as would be expected, since the sampling sites were located in different types of areas; industrial, commercial, residential and rural. In general, acetone was the most abundant carbonyl at all sites. The highest carbonyl concentrations were found at the Cuauhtémoc site, with exception of acetone, which was somewhat higher in Coyoacán. Concentrations of propionaldehyde and butyraldehyde were much lower at all sites. Baez et al., (2006) [14], in a previous study also reported lower levels of these carbonyls. Sin et al., (2001) [15] have previously reported that carbonyls with increasing number of $\mathrm{C}$ atoms are less abundant in the ambient air. The lowest concentration of all carbonyls was found in Morelos, the rural sampling site; not even butyraldehyde was detected.

Fig. (1) illustrated the seasonal variations in concentration observed during the sampling period at the four sites. The results of the two years were considered together, since differences in concentration between years were not significant $(p \leq 0.05)$. Higher concentrations were observed in winter at the Coyoacán and Tlalnepantla sites. During winter, air pollution levels were higher in the metropolitan area, enhanced by almost daily temperature inversions. These levels decreased significantly in summer and autumn, but the highest levels were observed in spring at the Cuauhtémoc site. Vehicle emissions in the MCMA are
Table 1. Arithmetic Mean, Minimum, Maximum and Standard Deviation Concentrations $\left(\mu \mathrm{g} \mathrm{m}^{-3}\right)$ of the Carbonyls Determined in Outdoor Air, for Each Site, Over the Sampling Period (2006-2007). N=56 Samples in Each Site

\begin{tabular}{|l|c|c|c|c|}
\hline & Coyoacan & Cuauhtémoc & Tlalnepantla & Morelos \\
\hline \hline Formaldehyde \\
\hline Arithmetic mean & 8.95 & 12.53 & 7.66 & 3.52 \\
\hline Minimun & 1.01 & 4.05 & 1.00 & 0.99 \\
\hline Maximun & 25.38 & 40.90 & 17.71 & 9.72 \\
\hline Standard deviation & 5.48 & 7.61 & 4.26 & 1.89 \\
\hline Acetaldehyde & \multicolumn{5}{|l}{} \\
\hline Arithmetic mean & 9.81 & 11.04 & 6.59 & 3.49 \\
\hline Minimun & 2.38 & 2.77 & 1.12 & 0.68 \\
\hline Maximun & 25.56 & 30.02 & 16.83 & 11.97 \\
\hline Standard deviation & 5.38 & 6.62 & 3.83 & 2.04 \\
\hline Acetone & & & & \\
\hline Arithmetic mean & 12.61 & 11.90 & 9.01 & 4.34 \\
\hline Minimun & 0.97 & 3.67 & 1.22 & 0.41 \\
\hline Maximun & 40.01 & 25.00 & 21.67 & 10.27 \\
\hline Standard deviation & 8.45 & 5.57 & 5.46 & 2.36 \\
\hline Propionaldehyde & & & & \\
\hline Arithmetic mean & 2.04 & 2.26 & 1.39 & 0.71 \\
\hline Minimun & 0.59 & 0.55 & 0.28 & 0.50 \\
\hline Maximun & 5.60 & 6.96 & 3.50 & 1.16 \\
\hline Standard deviation & 1.10 & 1.42 & 0.75 & 0.18 \\
\hline Butyraldehyde & \multicolumn{5}{|l|}{} \\
\hline Arithmetic mean & 1.19 & 1.49 & 1.21 & nd \\
\hline Minimun & 0.56 & 1.01 & 1.00 & nd \\
\hline Maximun & 2.95 & 1.48 & nd \\
\hline Standard deviation & 0.32 & 0.62 & 0.17 & nd \\
\hline
\end{tabular}

nd.- not detected.

relatively constant throughout the year because traffic density does not vary significantly between seasons. It is well known that vehicle emissions are sources of carbonyls. Formaldehyde and acetaldehyde in particular are mainly produced by vehicle emissions and photochemical oxidation of hydrocarbons. Secondary sources and sinks are also essential factors influencing ambient carbonyl concentrations. Sin et al., (2001) [15] reported that higher ambient temperatures and stronger solar radiation in summer not only enhance carbonyl-generating photochemical reactions, but also accelerate the photolysis of secondary carbonyls to form hydroxyl radicals; the hydroxyl radicals in turn could act as further sinks for the carbonyls. Summer weather (heavy rains and tropical storms that occur in summer and early autumn with cloudy skies most of the day) 

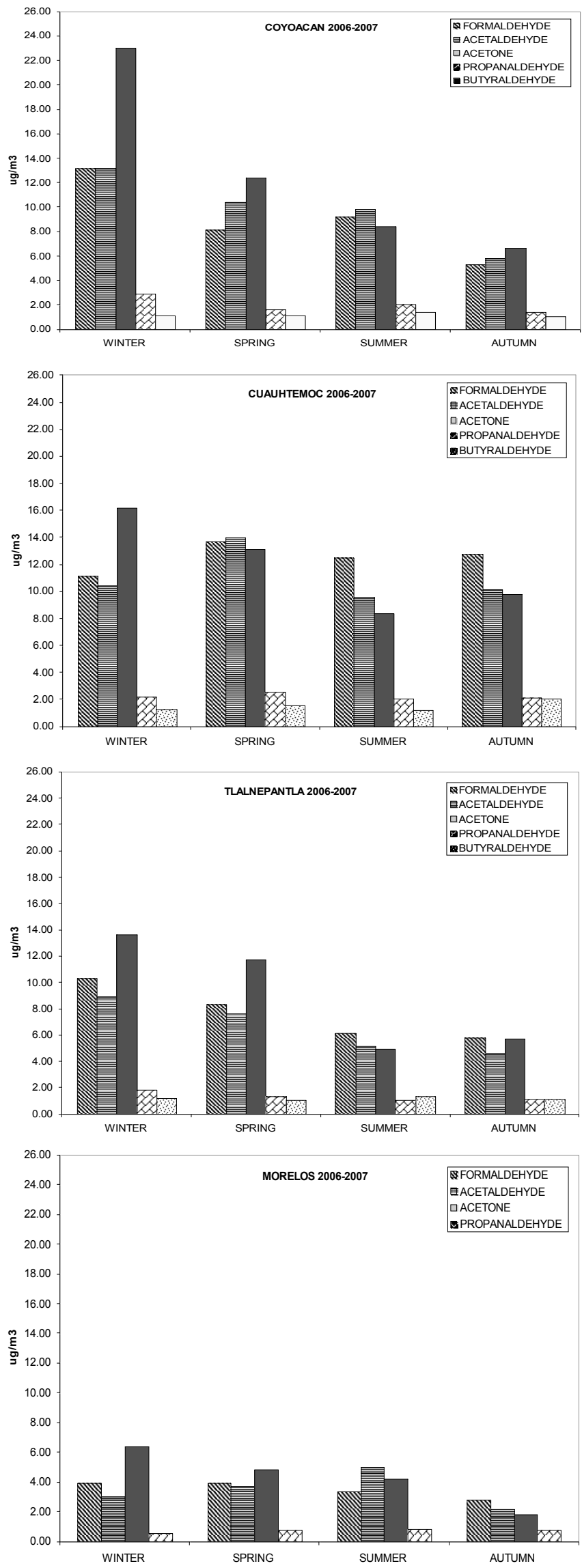

Fig. (1). Seasonal concentration variation found during 2006-2007, at the four sampling sites. are also major contributing factors that account for the relatively low mean concentration of formaldehyde and acetytaldehyde during the summer. Sin et al., (2001) [15] and Moussa et al., 2006 [16], also reported lower carbonyl concentrations during summer.

Aldehydes are the most reactive, and for formaldehyde and acetyaldehyde, the main reactions with $\mathrm{OH}$ radicals are:

$\mathrm{HCHO}+\mathrm{OH} \rightarrow \mathrm{HCO} \stackrel{\circ}{+} \mathrm{H}_{2} \mathrm{O}$ Rate constant $\left(\mathrm{cm}^{3}\right.$ molecule ${ }^{-1} \mathrm{~s}$ $\left.{ }^{1}\right)=1.1 \times 10^{-11}$

$\mathrm{HCO} \stackrel{\circ}{\mathrm{O}} 2 \rightarrow \mathrm{CO}+\mathrm{O} 2 \mathrm{H}$

$\mathrm{CH} 3 \mathrm{CHO}+\mathrm{OH} \rightarrow \mathrm{CH} 3 \mathrm{CO} \stackrel{\circ}{+} \mathrm{H} 2 \mathrm{O}$ Rate constant $\left(\mathrm{cm}^{3} \mathrm{~mol}-\right.$ ecule $\left.^{-1} \mathrm{~s}^{-1}\right)=1.6 \times 10^{-11}$

$\mathrm{CH} 3 \mathrm{CO} \stackrel{\circ}{+} \mathrm{O} 2 \rightarrow \mathrm{CH} 3 \mathrm{OCOO}$

Since acetaldehyde photolysis is much lower than that formaldehyde, and the reaction of acetaldehyde with hydroxyl radicals is slightly faster, reactions with hydroxyl radicals are likely to be more significant for the acetaldehyde sink than photolysis [10].

Photolytic rate constants $\mathrm{Kp}\left(\mathrm{s}^{-1}\right)$ and photolytic life time $(\tau)$ were estimated at the three MCMA sites for winter, spring and autumn at the hours of maximum actinic flux, 13:00 local time (True Standard Time TST, 12:10). The results indicated that total $\mathrm{Kp}\left(10^{-6} \mathrm{~s}^{-1}\right)$ was higher for formaldehyde than for acetaldehyde, with higher $\tau$ for formaldehyde [17], representing more rapid photochemical reactions and sinks for formaldehyde. Acetaldehyde concentrations were equal to or slightly lower than formaldehyde concentrations in all seasons and at all sampling sites. This can be attributed to the reformulation of gasoline with MTBE. The latitude of Mexico City is $19^{\circ} 20^{\prime}$ $\mathrm{N}$ and its elevation is $2200 \mathrm{~m}$ above sea level. The photolytic rate constants and photolytic lifetime are shown in Table $\mathbf{2}$ for Tlalnepantla in winter, Satélite in spring and Roma in summer. These actinic fluxes can contribute to the decrease in carbonyl concentrations in summer and autumn.

At the Cuauhtémoc site located in downtown Mexico City, the highest concentrations were observed in spring with small differences in concentration for the other three seasons. The low variation of carbonyl concentrations is a result of high traffic density throughout the year on heavily traveled avenues and narrow streets, which suggest that vehicle exhaust may be the primary source of carbonyls.

At the Morelos site, small differences in carbonyl concentrations were observed between winter, spring and summer, with the lowest values in autumn. The values were consistent with rural concentrations, suggesting lower emissions from vehicles and from secondary sources by photo-oxidation of hydrocarbons and sinks by pholtolytic reactions.

Fig. (2) shows the four-season average carbonyl concentrations for day and night samples. It can be observed that the highest values corresponded to daytime; suggesting that motor vehicle emissions are the main source of the 
Table 2. Photolytic Rate Constants in Formaldehyde and Acetaldehyde Photolysis, at $19^{\circ} \mathrm{N}$ Latitude (Mexico City)

\begin{tabular}{|c|c|c|c|c|c|c|c|c|c|}
\hline Date & Site & $\begin{array}{l}\text { Hour } \\
\text { Local }\end{array}$ & T.S.T. & $\begin{array}{c}\text { HCHO } \\
\text { ppbv }\end{array}$ & $\begin{array}{c}\text { Kp Total }\left(10^{-6} \mathrm{~s}^{-1}\right) \\
\text { HCHO }\end{array}$ & $\begin{array}{c}\text { T (Tour) } \\
\text { HCHO }\end{array}$ & $\underset{\text { ppbv }}{\mathrm{CH}_{3} \mathrm{CHO}}$ & $\begin{array}{c}\text { Kp Total }\left(10^{-6} \mathbf{s}^{-1}\right) \\
\mathrm{CH}_{3} \mathrm{CHO}\end{array}$ & $\begin{array}{l}\text { T (Tour) } \\
\mathrm{CH}_{3} \mathrm{CHO}\end{array}$ \\
\hline 6-Nov-96 & Tlalnepantla (winter) & $3: 00$ & $2: 39$ & 25.54 & 55.7 & 4.98 & 12.50 & 7.96 & 34.89 \\
\hline 13-Aug-97 & Roma (summer) & $13: 00$ & $12: 18$ & 45.06 & 64.1 & 4.33 & 44.07 & 10.44 & 26.60 \\
\hline 21-Mar-97 & Satelite (spring) & $13: 00$ & $12: 16$ & 10.16 & 64.0 & 4.34 & 5.71 & 10.40 & 26.70 \\
\hline
\end{tabular}

carbonyls, since vehicle traffic volumes are considerably lower at night, implying lower emissions.

Table 3 shows a comparison between 2001 and 2007 data. Formaldehyde concentrations decreased significantly in Coyoacán (15\%) and Tlalnepantla (48\%); but remained almost the same at the Cuauhtémoc site. Acetaldehyde concentrations increased by $91 \%$ in Coyoacán and $90.6 \%$ in Cuauhtémoc, but only $25 \%$ in Tlalnepantla. Acetone increased by $45 \%$ and $24 \%$ in Coyoacán and Cuauhtémoc respectively, and decreased by $10.5 \%$ in Tlalnepantla. It is difficult to explain the differences in concentrations between years. The increase in motor vehicles from 3.5 million in 2001 to 4.3 million in 2007 could be one factor. This decrease in formaldehyde can be attributed to enforcement of the law that all new automobiles had to have a catalytic converter from 1995 on. Currently more than $60 \%$ of cars have a catalytic converter. After the reformulation of Mexican gasoline with MTBE, higher amounts of acetaldehyde were emitted into the atmosphere.

\subsection{Correlations}

Spearman rank correlations were applied to all data collected at the four sampling sites. Table 4 shows the correlation matrix. It can be observed that high positive correlations were obtained between formaldehyde and acetaldehyde at the Coyoacán, Cuauhtémoc and Tlalnepantla sites and good correlation between acetone and propionaldehyde. The lowest carbonyl concentrations and lowest correlations were found at the rural Morelos site.

The strong correlation between formaldehyde and acetaldehyde throughout the study period suggests that these aldehydes are coming from common sources. In the MCMA, the main sources of these carbonyls are motor vehicle emissions, since in this zone more than four million vehicles are on the road daily. In November 1989, five percent MTBE was added to gasoline to reduce carbon monoxide and hydrocarbon emissions [18]. According to Anderson et al., (1996) [10], MTBE increases the emission of formaldehyde and acetaldehyde by comparable amounts. The high correlation found between acetone, formaldehyde and acetetaldehyde seems to indicate a common anthropogenic source.

It has been reported that secondary reactions could explain the acetone amounts in the ambient air. Acetone is formed by ozone reactions with some alkenes, and it is the main end product of $\mathrm{OH}$ radical oxidation of propanone, isobutene, isopentene and higher isoalkanes. It has been suggested that oxidation of propane is the main source of acetone [19]. Propane is the main constituent of liquefied petroleum gas, which is the fuel most commonly used in hotels, houses and many small industries in the MCMA. It could thus be an important source of acetone in MCMA.

Shepson et al., (1991) [20] and Pozanzini et al., (1996) [21], found that the ratios between formaldehyde and acetaldehyde are usually larger $(>7)$ for rural than for urban areas $(0.7$ to 3$)$ and stated that these ratios may indicate a biogenic source of formaldehyde. Grosjean (1992) [22] reported that the ratios often show large variations. In this study, however, relatively small variations were found in all data; ratios from winter, spring, summer and autumn generally varied from 0.77 to 1.19 . Only in Morelos in winter did the ratio reach 1.30. The levels found in this study are somewhat lower than the data reported by Grosjean et al., (1990), an average value of 1.7 from 17 urban cities in different countries. Our results can be considered to correspond to an urban area.

Table 5 compares carbonyl levels in Mexico City with those in other cities. Formaldehyde and acetone concentrations were higher in Beijing and Guangzhou than in Mexico. These cities have been reported to have highly polluted atmospheres [23], but the acetaldehyde level was higher in Mexico. The lowest values of all carbonyls are from Lille Valby, Denmark [24]. In Rio de Janeiro, Brazil, formaldehyde and acetaldehyde levels were close to those of Mexico. Brazilian vehicle fuel is alcohol-based and its combustion emits high levels of acetaldehyde [25].

\subsection{Factor Analysis}

To assess the relationships between concentrations of the carbonyls studied, factor analysis (Principal Component Analysis) was applied.

Table 6 shows the factor loading normalized with varimax rotation. Varimax rotation aims to maximize the variance of square normalized factor loading across variables for each factor and makes interpretation easier. Three factors from the principal component analysis were sufficient to explain $85.61 \%$ of the total variance. Factor 1 explained $54.2 \%$ of the total variance, with high loading on formaldehyde, acetaldehyde and acetone in Coyoacán and Tlalnepantla, and moderate loading on acetone and formaldehyde in Morelos. The high loadings on formaldehyde, acetaldehyde and acetone suggest that these carbonyls come from anthropogenic sources (vehicle emissions), although as noted above, acetone also comes from photochemical reactions. The moderate loadings on formaldehyde and acetaldehyde in Morelos also seem to indicate a contribution from anthropogenic origins. These findings are supported by the high correlations among these 

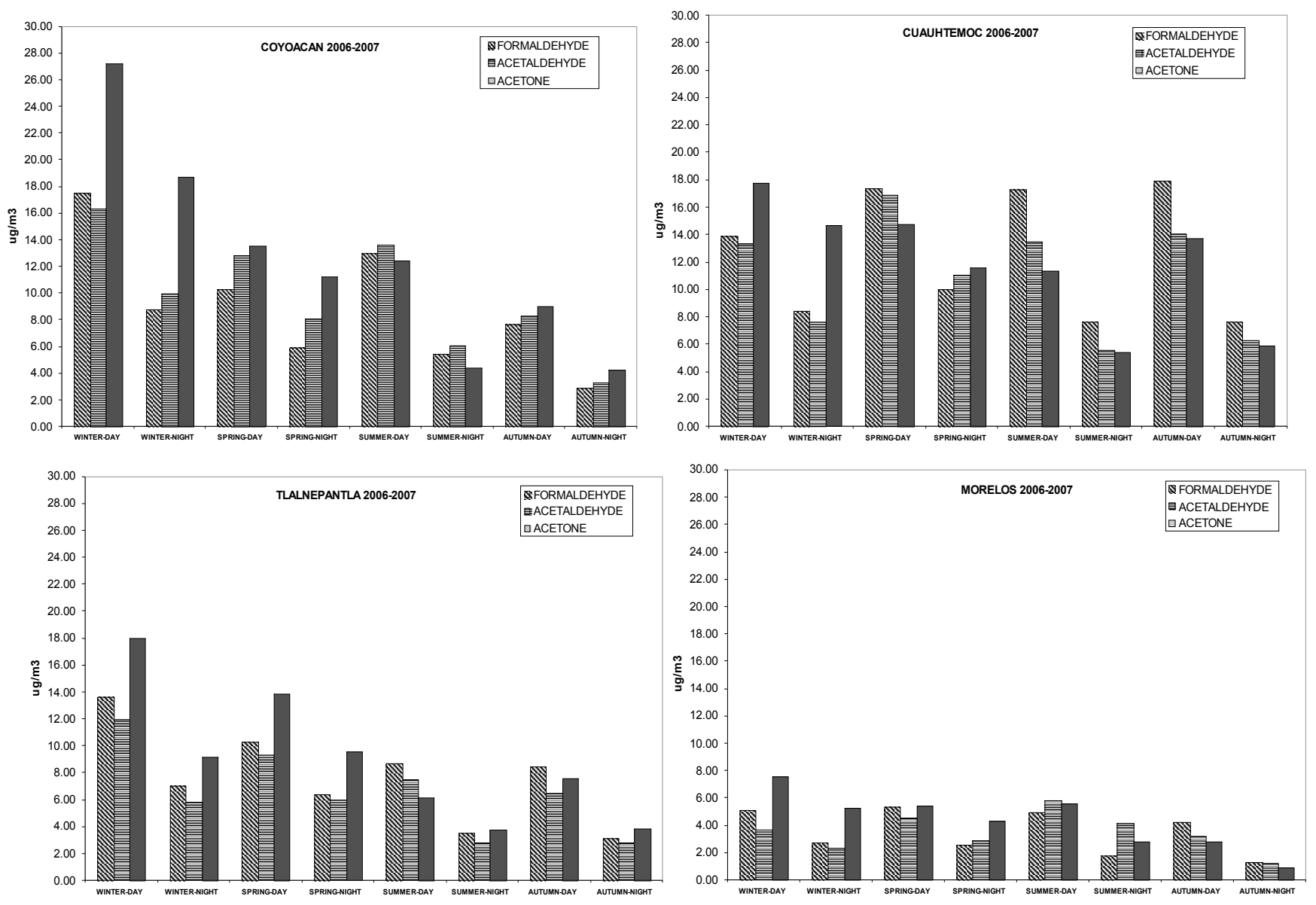

Fig. (2). The four season average concentrations corresponding to day and night time measurements.

carbonyls. Factor 2 indicates a high loading on formaldehyde and acetaldehyde and moderate loading on acetone in Cuauhtémoc, explaining $32 \%$ of the total variance. These results also indicate a contribution from anthropogenic sources.

\section{CONCLUSIONS}

Concentrations of $\mathrm{C}_{1}$ to $\mathrm{C}_{5}$ carbonyl compounds were measured at three sites (residential, downtown and industrial) in the MCMA and one in a rural wooded area in the state of Morelos. As expected, the concentrations varied according the characteristics of the sampling sites. Although propionaldehyde and butyraldehyde were present, concentrations were close to the detection limit. At some sites, butyraldehyde was not even detected; for this reason only $\mathrm{C}_{1}, \mathrm{C}_{2}$ and $\mathrm{C}_{3}$ were considered in the discussion of this paper. The variation in carbonyl levels was strongly dependent on motor vehicle traffic density in the MCMA, as was shown by the nighttime results, since traffic decreases significantly at night. The strong correlations between $\mathrm{C}_{1}-\mathrm{C}_{2}$ and $\mathrm{C}_{3}$ indicated that motor vehicle exhaust is the main source of these carbonyls. The lower concentrations observed in summer and autumn indicated that photochemical reactions and local meteorological conditions can account for the decrease in these seasons.

Currently a more intensive effort to measure carbonyls is underway, in which carbon monoxide measurements are included in order to determine the anthropogenic origin of the principal carbonyls more precisely, independently of photochemical reactions.

Table 3. Comparison Among the Carbonyls Concentration Between 2001 and 2007 Years, at the 3 Sampling Sites

\begin{tabular}{|c|c|c|c|c|c|c|c|c|c|}
\hline & \multicolumn{3}{|c|}{ Formaldehyde } & \multicolumn{3}{c|}{ Acetaldehyde } & \multicolumn{3}{c|}{ Acetone } \\
\cline { 2 - 11 } & $\mathbf{2 0 0 1}\left(\boldsymbol{\mu g} / \mathbf{m}^{3}\right)$ & $\mathbf{2 0 0 7}\left(\boldsymbol{\mu g} / \mathbf{m}^{3}\right)$ & $\mathbf{\% ~ D I F . ~}$ & $\mathbf{2 0 0 1}\left(\boldsymbol{\mu g} / \mathbf{m}^{3}\right)$ & $\mathbf{2 0 0 7}\left(\boldsymbol{\mu g} / \mathbf{m}^{3}\right)$ & $\%$ DIF. & $\mathbf{2 0 0 1}\left(\boldsymbol{\mu g} / \mathbf{m}^{3}\right)$ & $\mathbf{2 0 0 7}\left(\boldsymbol{\mu g} / \mathbf{m}^{3}\right)$ & $\% \mathbf{~ D I F . ~}$ \\
\hline \hline Coyoacan & 9.33 & 7.97 & -14.5 & 4.73 & 9.04 & +91.0 & 6.23 & 10.82 & +42.4 \\
\hline Cuauhtémoc & 10.93 & 10.59 & -3.0 & 5.20 & 10.94 & +90.6 & 8.70 & 11.47 & +24.1 \\
\hline Tlalnepantla & 13.80 & 7.13 & -48.0 & 7.86 & 6.26 & -25.0 & 9.96 & 9.01 & -10.5 \\
\hline
\end{tabular}

$\%$ DIF $=$ difference percentage, $(-)$ decrement, $(+)$ increment. 
Table 4. Spearman Rank Correlations" Among Outdoor Carbonyl Concentrations (2006-2007). Number of Samples in Each Site = 56

\begin{tabular}{|c|c|c|c|c|}
\hline & Formaldehyde & Acetaldehyde & Acetone & Propionaldehyde \\
\hline \multicolumn{5}{|l|}{ COYOACAN } \\
\hline Formaldehyde & 1.00 & & & \\
\hline Acetaldehyde & 0.92 & 1.00 & & \\
\hline Propionaldehyde & 0.53 & 0.50 & 0.44 & 1.00 \\
\hline \multicolumn{5}{|l|}{ CUAUHTÉMOC } \\
\hline Formaldehyde & 1.00 & & & \\
\hline Acetaldehyde & 0.88 & 1.00 & & \\
\hline \multicolumn{5}{|c|}{ TLALNEPANTLA } \\
\hline Formaldehyde & 1.00 & & & \\
\hline Acetaldehyde & 0.95 & 1.00 & & \\
\hline Acetone & 0.82 & 0.86 & 1.00 & \\
\hline Propionaldehyde & 0.65 & 0.59 & 0.55 & 1.00 \\
\hline \multicolumn{5}{|l|}{ MORELOS } \\
\hline
\end{tabular}

*Significant at $\mathrm{p} \leq 0.05$.

Table 5. Mean Concentrations $\left(\mu \mathrm{g} \mathrm{m}^{-3}\right)$ of Formaldehyde, Acetaldehyde and Acetone in Other Countries

\begin{tabular}{|l|l|c|c|c|c|}
\hline \multicolumn{1}{|c|}{ Location } & \multicolumn{1}{|c|}{ Sampling Time } & Formaldehyde & Acetaldehyde & Acetone & Reference \\
\hline \hline Beijing, China & November 2004-October 2005 & 14.8 & 10.2 & 16.6 & Pang and Mu, (2006) \\
\hline Beirut, Lebanon & August-October 2004 & 5.7 & 4.1 & 12.9 & Moussa et al. (2006) \\
\hline Guangzhou, China & June-September 2003 & 13.8 & 8.3 & 17.8 & Feng et al. (2005) \\
\hline Hong Kong, China & October 1997-September 2000 & 4.9 & 2.4 & 1.1 & Sina et al. (2001) \\
\hline Rio de Janeiro, Brazil & May-November 2000 & 10.8 & 10.4 & 4.1 & Grosjean et al. (2002) \\
\hline Lile Valby, Denmark & May-July 1995 & 1.5 & 1.4 & 4.5 & Christensen et al. (2000) \\
\hline Mexico City, Downtown-Mexico & 2006-2007 & 12.53 & 11.04 & 11.90 & Present study \\
\hline
\end{tabular}


Table 6. Factor Statistical 6.4 Analysis for All Data and All Variables. Factor Loading Normal Varimax Extraction. Principal Components (Bold Numbers are Significant at $>0.5$ )

\begin{tabular}{|l|c|c|c|}
\hline \multicolumn{1}{|c|}{ Variable } & Factor 1 & Factor 2 & Factor 3 \\
\hline \hline Coyoacan-Formaldehyde & $\mathbf{0 . 8 0}$ & 0.21 & -0.07 \\
\hline Coyoacan-Acetaldehyde & $\mathbf{0 . 8 2}$ & 0.24 & 0.003 \\
\hline Coyoacan-Acetone & $\mathbf{0 . 8 0}$ & 0.06 & 0.03 \\
\hline Cuauhtemoc-Formaldehyde & $\mathbf{0 . 8 5}$ & $\mathbf{0 . 9 4}$ & 0.003 \\
\hline Cuauhtemoc-Acetaldehyde & $\mathbf{0 . 8 9}$ & $\mathbf{0 . 9 2}$ & 0.06 \\
\hline Cuauhtemoc-Acetone & $\mathbf{0 . 8 9}$ & $\mathbf{0 . 5 6}$ & 0.16 \\
\hline Tlalnepantla-Formaldehyde & 0.10 & 0.35 & 0.20 \\
\hline Tlalnepantla-Acetaldehyde & 0.22 & 0.29 & 0.21 \\
\hline Tlalnepantla-Acetone & 0.34 & 0.09 & 0.23 \\
\hline Morelos-Formaldehyde & $\mathbf{0 . 5 3}$ & $\mathbf{0 . 5 5}$ & 0.08 \\
\hline Morelos-Acetadehyde & 0.29 & $\mathbf{0 . 5 9}$ & -0.002 \\
\hline Morelos-Acetone & $\mathbf{0 . 6 7}$ & 0.29 & 0.09 \\
\hline \% Total variance & 54.20 & 32.02 & 14.11 \\
\hline
\end{tabular}

\section{ACKNOWLEDGEMENTS}

This study was partially supported by Dirección General de Asuntos Académicos (PAPITT), Universidad Nacional Autónoma de México. Proyecto N100607. And to Carlos Contreras for his help in the computing work.

\section{REFERENCES}

[1] Granby K, Christensen CS, Lohse C. Urban and semi-rural observations of carboxylic acids and carbonyls. Atmos Environ 1997; 31: 1403-1415.

[2] Zhang J, Smith KR. Emissions of carbonyl compounds from various cookstoves in China. Environ Sci Technol 1999; 33: 23112320.

[3] Grosjean E, Williams II EL, Grosjean D. Ambient levels of formaldehyde and acetaldehyde in Atlanta, Georgia. J Air Waste Manage Assoc 1993; 43: 469-474.

[4] Carlier P, Hannachi H, Mouvier G. The chemistry of carbonyl compounds in the atmosphere: a review. Atmos Environ 1986; 20: 2079-2099.

[5] Lary DJ, Shallcross DE. Central role of carbonyl compounds in atmospheric chemistry. J Geophys Res 2000; 105: 771-778.

[6] Grosjean D, Miguel AH, Tavares TM. Urban air pollution in Brazil: acetaldehyde and other carbonyls. Atmos Environ 1990; 24B: 101-106.

[7] Williams ID, Revitt DM, Hamilton RS. A comparison of carbonyl compound concentrations at urban roadside and indoor sites. Sci Total Environ 1996; 189: 475-483.
[8] IARC. Overall evaluations on carcinogenicity to humans. Monographs series. International Agency for Research on Cancer, Lyon, France, 2004, vol. 88.

[9] Stump FD, Knapp KT, Ray WD. Seasonal impact of blending oxygenated organics with gasoline on motor vehicle tailpipe and evaporative emissions. J Air Waste Manage Assoc 1990; 40: 872880.

[10] Anderson LG, Lanning JA, Barrell R, Miyagishima J, Jones RH, Wolfe P. Sources and sinks of formaldehyde and acetaldehyde: an analysis of Denver's ambient concentration data. Atmos Environ 1996; 30: 2113-2123.

[11] De More WB, Sander SP, Golden DM, et al. Chemical kinetics and photochemical data for the use of stratospheric modeling: Evaluation Number 10. JPL Publication 92-20, Jet Propulsion Labs, Pasadena, CA, USA, 1992.

[12] Báez AP, Padilla H, Torres MC, Belmont R. Ambient levels of carbonyls in Mexico City. Atmos Environ Atmósfera 2000; 13: 121-131.

[13] Waters. Waters Sep-Pak DNPH-Silica cartridge. Care and use Manual. Waters Corporation, Milford, MA, 1994.

[14] Baez AP, Padilla H, García R, Belmont R, Torres MC. Measurement of indoor-outdoor carbonyls at four residential homes in Mexico City metropolitan area. Int J Environ Pollution 2006; 26: 90104.

[15] Della SWM, Wong Y-C, Louie PKK. Trends of ambient carbonyls compounds in the urban environment of Hong Kong. Atmos Environ 2001; 35: 5961-5969.

[16] Samar GM, El-Fadel M, Saliba NA. Seasonal, diurnal and nocturnal behaviors of coger carbonyl compounds in the urban environment of Beirut, Lebanon. Atmos Environ 2006, 40: 2459-2468.

[17] Báez AP, Torres MC, García R, Padilla H. Carbonyls in the Metropolitan Area of Mexico City: Calculation of Total Photolytic Rate Constants $\mathrm{Kp}\left(\mathrm{s}^{-1}\right)$ and Photolytic Lifetime ( $\mathrm{t}$ ) of Ambient Formaldehyde and Acetaldehyde. Environ Sci Pollution Res 2002; 9: 230233.

[18] GDF. Inventario de emisiones Zona Metropolitana del Valle de México. Gobierno del Distrito Federal, Secretaría del Medio Ambiente, Dirección General de Gestión Ambiental del Aire, 2004.

[19] Chatfield RB, Gardner EP, Calvert JG. Sources and sinks of acetone in the troposphere: behavior of reactive hydrocarbons and a stable product. J Geophys Res 1987; 92(D4): 4208-4216.

[20] Shepson, BP, Hastie DR, Schiff HI, Polizzi M. Atmospheric concentrations and temporal variations of $\mathrm{C} 1-\mathrm{C} 3$ carbonyl compounds at two rural sites in Central Ontario. Atmos Environ 1991; 25A: 2001-2015.

[21] Possanzini M, Di Palo V, Patricca R, Fratarcangeli R, Brocco D. Measurements of lower carbonyls in Rome ambient air. Atmos Environ 1996; 30: 3757-3764.

[22] Grosjean D. Discussion: atmospheric concentrations and temporal variations of $\mathrm{C} 1-\mathrm{C} 3$ carbonyl compounds at two rural sites in central Ontario. Atmos Environ 1992; 26 A: 349-351.

[23] Pang X, Mu Y. Seasonal and diurnal variations of carbonyl compounds in Beijing ambient air. Atmos Environ 2006; 40: 63136320.

[24] Christensen CS, Skov H, Nielsen T, Lohse C. Temporal variation of carbonyl compounds concentrations at a semi-rural site in Demark. Atmos Environ 2000; 34: 287-296.

[25] Miguel AH, De Aquino Neto FR, Cardoso JN, et al. Characterization of indoor air quality in the cities of Sao Paulo and Rio de Janeiro, Brazil. Environ Sci Technol 1995; 29: 338-345. 